\title{
Differential Roles of Splanchnic and Peripheral Tissues in the Pathogenesis of Impaired Glucose Tolerance
}

Luigi Saccà, Giuseppe Orofino, Antonio Petrone, and Carlo Vigorito

Institute of Internal Medicine I, Second School of Medicine, University of Naples, Naples, Italy

A altered glucoregulatory response to a glucose load in subjects with impaired glucose tolerance, we selectively quantitated the components of net splanchnic glucose balance, i.e., splanchnic glucose uptake and hepatic glucose output, as well as peripheral glucose uptake, by combining $\left[3-{ }^{3} \mathrm{H}\right]$ glucose infusion with hepatic vein catheterization. After intravenous glucose infusion $(6$ $\mathrm{mg} \cdot \mathrm{kg}^{-1} \cdot \mathrm{min}^{-1}$ for $90 \mathrm{~min}$ ), blood glucose rose to $172 \pm 7 \mathrm{mg} / \mathrm{dl}$ in controls and $232 \pm 13 \mathrm{mg} / \mathrm{dl}$ in subjects with impaired glucose tolerance $(P<0.01)$. The response of plasma insulin did not differ significantly between the two groups ( $29 \pm 4$ vs. $40 \pm 10 \mu \mathrm{U} / \mathrm{ml}$ at $90 \mathrm{~min}$ in control and in glucose intolerant subjects, respectively; $P=\mathrm{NS}$ ). In both groups, glucose infusion caused the net splanchnic glucose balance to switch from the net output of the basal state to a net glucose uptake. However, this effect was more marked in subjects with impaired glucose tolerance than in control subjects (at 90 min: $2.83 \pm 0.53$ vs. $1.60 \pm 0.18 \mathrm{mg} \cdot \mathrm{kg}^{-1} \cdot \mathrm{min}^{-1}$, respectively; $P<0.05$ ). The different pattern of splanchnic glucose balance was entirely accounted for by a greater rise in splanchnic glucose uptake in the group of glucose intolerants, as the suppression of endogenous glucose output by the glucose load was practically complete in both groups. In contrast, glucose uptake by peripheral tissues increased considerably less in subjects with impaired glucose tolerance than in controls $\left(2.2-2.6\right.$ vs $3.6-4.1 \mathrm{mg} \cdot \mathrm{kg}^{-1} \cdot \mathrm{min}^{-1}$, respectively, between 60 and $90 \mathrm{~min} ; P<0.01-0.001$ ). Furthermore, a net splanchnic lactate uptake was present in the basal

Received for publication 2 December 1983 and in revised form 21 February 1984.

J. Clin. Invest.

(C) The American Society for Clinical Investigation, Inc. $0021-9738 / 84 / 06 / 1683 / 05 \quad \$ 1.00$

Volume 73, June 1984, 1683-1687

state, which was inhibited by the glucose load and switched to a comparable net lactate output in both groups.

These results indicate that the mechanism responsible for the altered glucoregulation in subjects with impaired glucose tolerance resides entirely in the peripheral tissues whose ability to dispose of a glucose load is drastically reduced. On the other hand, no defect is detectable in any of the explored mechanisms regulating splanchnic glucose metabolism during the disposal of an exogenous glucose load.

\section{Introduction}

Glucose intolerance is a cardinal feature of diabetes mellitus. In non-insulin-dependent, type II diabetics as well as in subjects with impaired glucose tolerance (IGT),' the presence of insulin resistance is also well documented and regarded as one of the principal factors responsible for the altered glucose homeostasis (1-5). Yet, the kinetic mechanisms whereby glucose intolerance originates in circumstances of insulin resistance have not been completely elucidated. Previous tracer studies $(3,5)$ have demonstrated that a defect in overall glucose utilization exists both in type II diabetes as well as in IGT. These disorders however, have not been further characterized with respect to the specific sites or tissues implicated in the defective glucose utilization. In particular, data are not available regarding the relative roles played by splanchnic and peripheral tissues in the genesis of IGT. Furthermore, it is still unestablished in IGT subjects if the mechanisms that regulate hepatic glucose production respond normally to the suppressive effect of a glucose load.

In the current study, we attempted to clarify these issues by combining the hepatic vein catheterization technique with the tracer method $\left(\left[3-{ }^{3} \mathrm{H}\right] \mathrm{glucose}\right)$ so as to be able to quantitate selectively the splanchnic and peripheral components in the disposal of an exogenous glucose load. The study was performed in a group of subjects with IGT (6) in an attempt to determine which alterations of the glucoregulatory system characterize this

1. Abbreviations used in this paper: IGT, impaired glucose tolerance; NSGB, net splanchnic glucose balance; SGU, splanchnic glucose uptake. 
Table I. Clinical and Metabolic Features of the Study Groups

\begin{tabular}{|c|c|c|c|c|c|c|}
\hline & $\mathrm{n}$ & $\begin{array}{l}\text { Sex } \\
M / F\end{array}$ & Age & $\begin{array}{l}\text { Relative } \\
\text { weight* }\end{array}$ & $\begin{array}{l}\text { Fasting } \\
\text { plasma } \\
\text { glucose }\end{array}$ & $\begin{array}{l}\text { Fasting } \\
\text { plasma } \\
\text { insulin }\end{array}$ \\
\hline & & & $y r$ & & $m g / d l$ & $\mu U / m l$ \\
\hline Controls & 7 & $5 / 2$ & $42 \pm 2$ & $0.99 \pm 0.02$ & $80 \pm 2$ & $7 \pm 1$ \\
\hline IGT & 6 & $4 / 2$ & $49 \pm 4$ & $1.03 \pm 0.02$ & $112 \pm 7$ & $16 \pm 5$ \\
\hline
\end{tabular}

Data represent means \pm SE. $n=$ number of subjects.

* Source: Documenta Geigy. Scientific Tables. 1970. K. Diem, editor. Ciba-Geigy, Basel.

abnormality, which for some patients represents an initial stage in the natural history of clinical diabetes. Thus, elucidation of the mechanisms leading to IGT may be potentially useful to improve our understanding of the pathophysiology of diabetes mellitus itself.

\section{Methods}

Subjects. The study group consisted of seven control subjects and six subjects with IGT as defined by the criteria of the National Diabetes Data Group (6). The clinical and metabolic characteristics of the subjects are given in Table I. Furthermore, all subjects studied were patients admitted to the Institute of Internal Medicine I of the University of Naples for elective cardiac catheterization for diagnostic purposes (coronary artery disease or aortic or mitral valve disease). None of them had a positive history of congestive heart failure or liver disease. Two patients (one control and one in the IGT group) were affected by angina pectoris and they took nitrates when necessary. The remainder were asymptomatic and required no therapy. The nature, purpose, and possible risks of the additional procedures were fully explained to each subject before his written consent to participate was obtained. The experimental protocol was approved by the Ethical Committee of the University of Naples School of Medicine.

Procedures. All subjects were studied in the postabsorptive state after a 12-15-h overnight fast. After the diagnostic procedures were completed, a main right-sided hepatic vein was catheterized as previously described $(7,8)$. For arterial blood sampling, a small teflon catheter was used, which replaced the arterial catheter inserted into the brachial artery during the diagnostic catheterization. Patency of the catheters was maintained by intermittent flusing with saline. During the experiment, the patients were allowed to remain as comfortable as possible and further potentially stressful maneuvers were avoided. At the time when the metabolic protocol was initiated, the patients were relaxed and any stress possibly caused by the diagnostic procedure had already subsided. This is also indicated by the fact that the basal parameters in the control group were within their normal range (see below). Furthermore, we have observed that plasma catecholamine levels in other patients studied in similar conditions are comparable to those usually found in resting normal subjects (Saccà, L., and R. S. Sherwin, unpublished observations).

At the beginning of each experiment, a priming dose of $\left[3-{ }^{3} \mathrm{H}\right] g l u c o s e$ $(40 \mu \mathrm{Ci})$ (Amersham, Buckinghamshire, England) and indocyanine green dye (Cardio-Green, Hynson, Westcott \& Dunning, Baltimore, MD) was injected through a peripheral vein, followed by a continuous infusion at a rate of $0.5 \mu \mathrm{Ci} / \mathrm{min}$ and $0.5 \mathrm{mg} / \mathrm{min}$, respectively, for the remainder of the study. After a 75-min equilibration period, unlabeled glucose was infused intravenously at a rate of $6 \mathrm{mg} \cdot \mathrm{kg}^{-1} \cdot \mathrm{min}^{-1}$ for $90 \mathrm{~min}$. Blood samples were withdrawn from the arterial and the hepatic vein catheters for chemical analyses and hepatic blood flow measurements in the basal state and at $15-\mathrm{min}$ intervals thereafter.

Analytical methods. Glucose (9) and lactate (10) concentration was measured in whole blood by using enzymatic procedures. The methods used for the determination of plasma immunoreactive insulin and glucagon have previously been described $(7,8)$. The plasma concentration of indocyanine green dye was determined spectrophotometrically. For the assay of $\left[3-{ }^{3} \mathrm{H}\right]$ glucose radioactivity, blood samples were deproteinized with $\mathrm{Ba}(\mathrm{OH})_{2}-\mathrm{ZnSO}_{4}$ and the supernatant was evaporated to dryness at $60^{\circ} \mathrm{C}$ to remove tritiated water. The dry residue was dissolved in $1 \mathrm{ml}$ of water and counted with $10 \mathrm{ml}$ of Insta-Gel (Packard Instruments, Inc., Downers Grove, IL) in a liquid scintillation system for at least $45 \mathrm{~min}$ for each sample, so as to reduce the counting error to $<0.6 \%$ ( $\pm 2 \mathrm{SD})$.

Calculations. Hepatic blood flow was estimated according to the method of Leevy et al. (11). Net splanchnic glucose balance (NSGB) and lactate balance were calculated as the product of the hepatic venousarterial (HV-A) blood concentration difference of either substrate and the estimated hepatic blood flow (EHBF). NSGB represents the sum of two independent processes, which may operate simultaneously within the splanchnic area, i.e., hepatic glucose output and splanchnic glucose uptake. The combined tracer-hepatic vein catheterization technique allows selective quantitation of these two processes to be achieved.

For splanchnic glucose uptake (SGU), the following equation was used: $\quad$ SGU $=$ arterial blood glucose $\times \mathrm{EHBF} \times(\mathrm{HV}-\mathrm{A})$ blood $[3-$ $\left.{ }^{3} \mathrm{H}\right]$ glucose/arterial blood $\left[3-{ }^{3} \mathrm{H}\right]$ glucose. Once NSGB and SGU are known, also hepatic glucose output (HGO) is determined since these parameters are linked by the relation: NSGB $=$ HGO - SGU. Glucose uptake by peripheral tissues (extra splanchnic) was estimated according to the formula: Peripheral glucose uptake $=$ systemic glucose delivery $-\mathrm{p} V \mathrm{dg} / \mathrm{dt}$, where the systemic glucose delivery is equal to net splanchnic glucose balance plus exogenously infused glucose; $p$ is the rapidly mixing compartment of the glucose space, assumed to be $0.70(12) ; V$ is the distribution volume of glucose, assumed to be $20 \%$ of body weight (13); $\mathrm{g}$ is blood glucose concentration. The values of $\mathrm{g}$ and $\mathrm{dg} / \mathrm{dt}$ were calculated by using a polynomial fitting procedure previously validated (14).

In the current approach, SGU may be equated to splanchnic glucose utilization (or consumption) to the extent that $\left[3-{ }^{3} \mathrm{H}\right]$ glucose uptake is reflective of true utilization of unlabeled glucose. If part of the [3${ }^{3} \mathrm{H}$ ]glucose taken up by the liver loses its tritium within the triosephosphate pool, only to be resynthetized without undergoing complete oxidation, the calculated rate of glucose uptake would slightly overestimate glucose utilization. Actually, the existence of a futile cycle for $\left[3-{ }^{3} \mathrm{H}\right]$ glucose is not as well established as in the case of $\left[2-{ }^{3} \mathrm{H}\right]$ glucose $(15,16)$. Furthermore, for a significant resynthesis of unlabeled glucose from $\left[3-{ }^{3} \mathrm{H}\right] \mathrm{glucose}$ to occur, it is required that glycolysis and gluconeogenesis operate simultaneously. This is very unlikely in the current experimental situation of combined hyperinsulinemia and hyperglycemia, which activate the glycolytic flux while inhibiting gluconeogenesis, as strongly suggested also by the lactate balance data (see Results).

Data are presented as the mean \pm SE. Statistical analysis was performed by the two-way analysis of variance (intragroup comparisons) or the $t$ test for unpaired samples (control vs. IGT subjects).

\section{Results}

As shown in Table II, arterial blood glucose was significantly higher in the IGT group than in controls both in the basal state as well as during exogenous glucose infusion $(P<0.01-0.001)$. At $90 \mathrm{~min}$, the net increment above base line was $89 \pm 5$ and $123 \pm 14 \mathrm{mg} / \mathrm{dl}$ in the control and IGT group, respectively $(P$ 
Table II. Effects of Glucose Infusion on Arterial Blood Glucose, Plasma Insulin, Plasma Glucagon, and Estimated Hepatic Blood Flow in Subjects with IGT and in Normal Control Subjects

\begin{tabular}{|c|c|c|c|c|c|c|c|}
\hline \multirow[b]{2}{*}{ Subjects } & \multicolumn{7}{|l|}{ Minutes } \\
\hline & 0 & 15 & 30 & 45 & 60 & 75 & 90 \\
\hline \multicolumn{8}{|c|}{ Arterial blood glucose, $m g / d l$} \\
\hline Control & $83 \pm 3$ & $120 \pm 4$ & $138 \pm 5$ & $153 \pm 6$ & $163 \pm 5$ & $169 \pm 7$ & $172 \pm 7$ \\
\hline IGT & $109 \pm 2$ & $150 \pm 3$ & $178 \pm 6$ & $196 \pm 8$ & $210 \pm 9$ & $220 \pm 10$ & $232 \pm 13$ \\
\hline \multicolumn{8}{|c|}{ Arterial plasma insulin, $\mu U / m l$} \\
\hline Control & $7 \pm 0.7$ & $14 \pm 0.5$ & $18 \pm 2$ & $20 \pm 4$ & $23 \pm 4$ & $25 \pm 9$ & $29 \pm 4$ \\
\hline IGT & $16 \pm 5$ & $23 \pm 8$ & $25 \pm 9$ & $26 \pm 9$ & $32 \pm 12$ & $37 \pm 11$ & $40 \pm 10$ \\
\hline \multicolumn{8}{|c|}{ Arterial plasma glucagon, $\mathrm{pg} / \mathrm{ml}$} \\
\hline Control & $109 \pm 15$ & & $90 \pm 10$ & & $84 \pm 8$ & & $81 \pm 10$ \\
\hline IGT & $123 \pm 20$ & & $96 \pm 14$ & & $88 \pm 9$ & & $91 \pm 10$ \\
\hline \multicolumn{8}{|c|}{ Hepatic blood flow, liter/min } \\
\hline Control & $1,391 \pm 167$ & $1,451 \pm 183$ & $1,432 \pm 145$ & $1,360 \pm 114$ & $1,343 \pm 97$ & $1,278 \pm 75$ & $1,409 \pm 131$ \\
\hline IGT & $1,134 \pm 68$ & $1,179 \pm 189$ & $1,283 \pm 207$ & $1,254 \pm 165$ & $1,154 \pm 158$ & $1,072 \pm 105$ & $1,208 \pm 131$ \\
\hline
\end{tabular}

Data are presented as mean $\pm \mathrm{SE}$. Base-line values $(0 \mathrm{~min})$ represent the mean of three observations in each subject taken at 10 -min intervals preceding glucose infusion.

$<0.05)$. Arterial plasma insulin increased fourfold after glucose infusion in the control group. In the subjects with IGT, plasma insulin levels were slightly higher than the corresponding values of the control subjects at all time points but the difference did not reach statistical significance. However, if the insulin response is expressed as percent change from base line, the increment observed in IGT subjects was significantly smaller $(153 \pm 48 \%$ vs. $317 \pm 53 \% ; P<0.05$ ). Arterial plasma glucagon fell significantly in response to the glucose load $(P<0.01)$ and no significant difference was observed between the two groups. Estimated splanchnic blood flow remained practically unchanged in both groups.

The response of splanchnic and peripheral glucose kinetics to the glucose load is illustrated in Fig. 1. In the basal state, net splanchnic glucose output tended to be lower in the subjects with IGT than in controls $(1.21 \pm 0.14$ vs. $1.58 \pm 0.1$ $\left.\mathrm{mg} \cdot \mathrm{kg}^{-1} \cdot \mathrm{min}^{-1}, 0.1>P>0.05\right)$. This difference was mainly attributable to hepatic glucose output $(1.98 \pm 0.15$ and $2.34 \pm 0.18$ $\mathrm{mg} \cdot \mathrm{kg}^{-1} \cdot \mathrm{min}^{-1}$ in the IGT and control group, respectively) as the basal values of splanchnic glucose uptake were very similar in the two groups $\left(0.71 \pm 0.05 \mathrm{mg} \cdot \mathrm{kg}^{-1} \cdot \mathrm{min}^{-1}\right.$ in controls and $0.79 \pm 0.15$ in subjects with IGT). Glucose administration caused the splanchnic glucose balance to switch from the basal situation of a net output to one of net glucose uptake in both groups of subjects. This response, however, was more pronounced in the IGT group than in controls $(P<0.05-0.025$ at 75 and $90 \mathrm{~min})$. The reversal of the net splanchnic balance was mediated by both suppression of hepatic glucose production and stimulation of splanchnic glucose disposal. However, while hepatic glucose output was virtually suppressed to zero in both groups, SGU rose to higher values in the subjects with IGT than in controls $\left(2.7-2.9\right.$ vs. $1.6-1.8 \mathrm{mg} \cdot \mathrm{kg}^{-1} \cdot \mathrm{min}^{-1}$ at $\left.75-90 \mathrm{~min}, P<0.05\right)$, thus accounting for the more pronounced reversal of NSGB observed in the IGT group. The basal values of peripheral glucose uptake were identical to those reported above for NSGB since a steady state was present. After glucose infusion, peripheral glucose uptake was stimulated in both groups, but the values attained in the subjects with IGT were considerably lower than

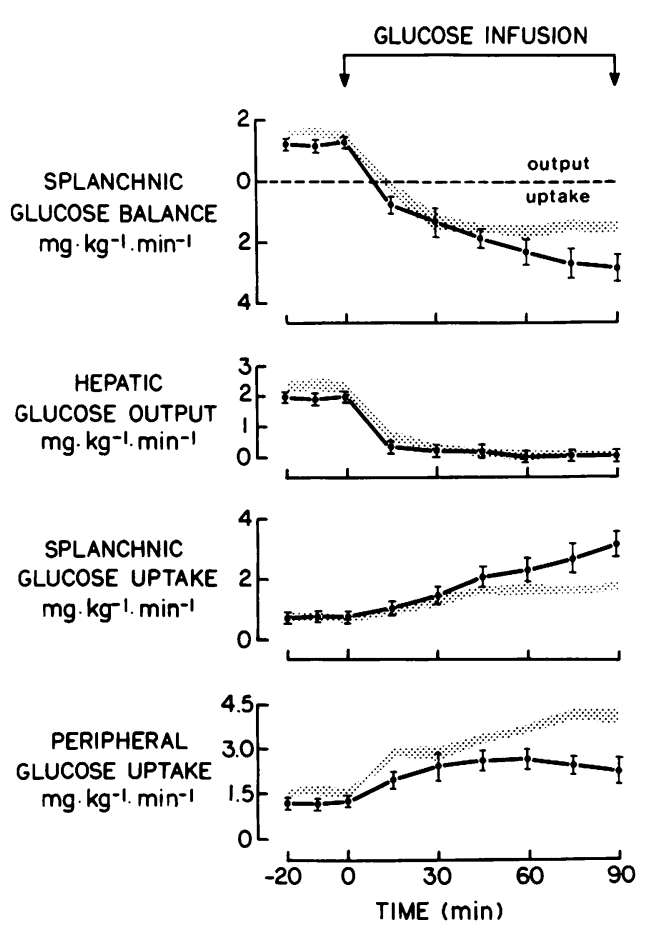

Figure 1. Response of splanchnic and peripheral glucose kinetics to intravenous glucose infusion $\left(6 \mathrm{mg} \cdot \mathrm{kg}^{-1} \cdot \mathrm{min}^{-1}\right)$ in subjects with IGT. The shaded area denotes the response of control subjects (mean $\pm \mathrm{SE}$ ). 
those in the control group $\left(2.2-2.6\right.$ vs. $3.6-4.1 \mathrm{mg} \cdot \mathrm{kg}^{-1} \cdot \mathrm{min}^{-1}$ between 60 and $90 \mathrm{~min}$ in the IGT and control groups, respectively; $P<0.01-0.001$ ). Glucosuria was either absent or of such a small extent so as not to affect the calculations of peripheral glucose disposal.

The changes in lactate metabolism are depicted in Fig. 2. In both groups, arterial blood lactate increased significantly above base line after glucose infusion $(P<0.05$ between 60 and 90 $\mathrm{min})$. As expected, in the basal state the splanchnic area was a site of net lactate utilization $(0.37 \pm 0.3$ and $0.30 \pm 0.1$ $\mathrm{mg} \cdot \mathrm{kg}^{-1} \cdot \mathrm{min}^{-1}$ in controls and IGT subjects, respectively, $P$ $=$ NS). After glucose infusion, splanchnic lactate uptake fell rapidly, switching to a net lactate output. No statistically significant difference was demonstrable between the two groups as to the changes in both blood lactate concentration and splanchnic lactate metabolism.

\section{Discussion}

Although IGT is a quite frequent metabolic condition, the kinetic mechanisms whereby this abnormality develops had not been thoroughly explored before this study. The current data demonstrate a marked reduction of glucose disposal by peripheral tissues in the subjects with impaired glucose tolerance. Furthermore, this appears to be the only mechanism responsible for the reduced ability of these subjects to dispose of a glucose load. The other components of the glucoregulatory response, i.e., splanchnic glucose uptake and endogenous glucose production, do not provide any contribution to the reduced glucose

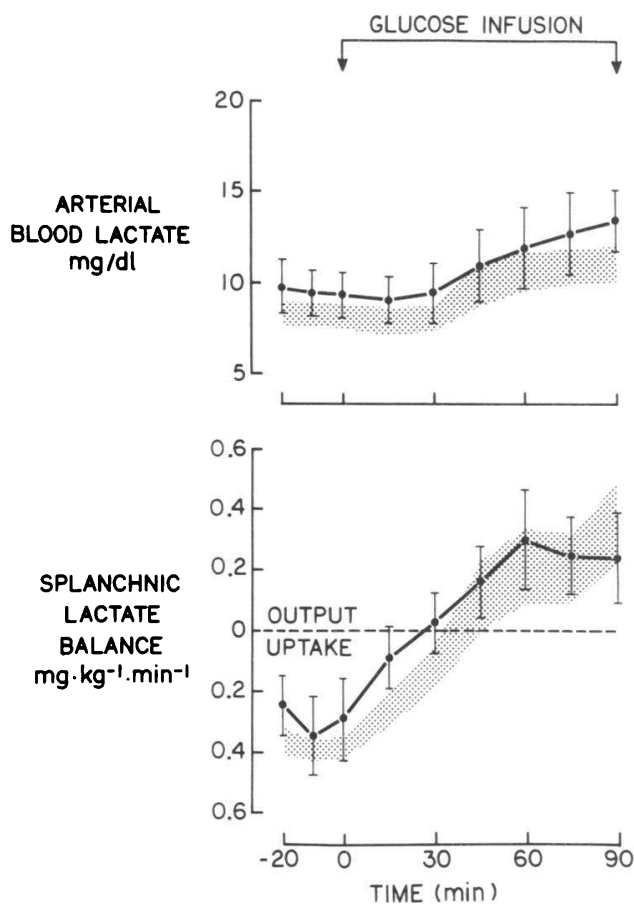

Figure 2. Changes in arterial blood lactate and splanchnic lactate balance during intravenous glucose infusion $\left(6 \mathrm{mg} \cdot \mathrm{kg}^{-1} \cdot \mathrm{min}^{-1}\right)$ in subjects with impaired glucose tolerance. The shaded area denotes the response of control subjects (mean $\pm \mathrm{SE}$ ). tolerance. Of particular interest is the fact that the response of splanchnic glucose uptake was even greater than in controls towards the end of the infusion period when the difference in blood glucose concentration was maximal. Since the absolute insulin levels were comparable in the two groups, it is possible that the more pronounced elevation of splanchnic glucose uptake in the subject with IGT was mediated by the relatively more accentuated hyperglycemia achieved in this group. Such an interpretation would not be in contrast with the reported inability of glucose per se to activate splanchnic glucose utilization, since this observation has been previously made in circumstances of acute insulin deficiency (7) while in the current study the splanchnic insulin availability was normal. Regardless of the mechanism underlying the greater splanchnic disposal in IGT subjects, the current data clearly establish that the splanchnic area does not play any causal role in the impaired ability of these subjects to handle a glucose load; rather it may serve to attenuate the consequences of the defective glucose disposal by peripheral tissues.

Previous studies using the euglycemic glucose clamp in conjunction with tritiated glucose have demonstrated that the insulin resistance of subjects with IGT is essentially mediated by a defect in overall glucose utilization (5). Due to the limitations inherent in the tracer method, those studies, however, have not provided specific information on the sites or tissues implicated in this defect. Yet, a role of the periphery in the defective glucose disposal could have been inferred since those experiments (5) were performed under conditions of euglycemia which is known to favor glucose uptake by peripheral tissues (17). In line with previous observations (5), the current study provides direct evidence for a key role of the periphery in the pathogenesis of impaired glucose tolerance. On the other hand, the entirely different role played by the splanchnic area, as emerges from our study, could not have been deduced from previous investigations since direct data on the splanchnic kinetic response to a glucose load in subjects with impaired glucose tolerance were not before available. In this context, it is pertinent to recall that earlier catheter studies performed in type II diabetics have shown a reduced splanchnic glucose retention after an oral glucose load (18). The extent to which a failure in splanchnic retention is attributable to a defect of splanchnic glucose uptake is uncertain in view of the multiple factors that regulate splanchnic glucose kinetics, especially after an oral load. However, even assuming these observations (18) as being truly reflective of impaired splanchnic glucose uptake in type II diabetics they would not be incompatible with the current demonstration of an efficient splanchnic glucose disposal in subjects with IGT. Rather, taking the data together, a general view might emerge, which indicates that while in IGT subjects the defect in glucose disposal is confined to the periphery, as the disease proceeds to overt diabetes and glucose tolerance deteriorates further, this defect might extend, thus also involving the splanchnic area.

After glucose infusion, endogenous glucose production was equally well suppressed in the subjects with IGT and in controls. Thus, this kinetic component does not appear to be involved in the genesis of the impaired glucose tolerance. It has been previously reported that in patients with IGT, hepatic glucose 
production is completely inhibited by maximally effective insulin concentrations but appears to be less suppressible than in normal subjects when the liver is exposed to physiologic insulin levels $(100 \mu \mathrm{U} / \mathrm{ml})(5)$. It should be noted, however, that those studies have examined the impact of insulin administration on glucose production in circumstances of euglycemia. It is not surprising, therefore, that in a different setting where hyperinsulinemia is associated with hyperglycemia, as in the current study, hepatic glucose production is completely suppressed, even in the presence of moderately elevated insulin levels, given the important contribution that glucose per se may provide in this context $(7$, 19, 20).

The causes responsible for the altered kinetic response to glucose administration in subjects with IGT may be multiple. A receptor, but not postreceptor, defect in insulin action has been previously demonstrated in these subjects (5). The possibility that abnormalities in insulin secretion may play some role should also be considered. In our study, although the absolute insulin increments after glucose infusion were similar in the two groups, the percent increase above base line was smaller in the subjects with IGT. Furthermore, the insulin response of these subjects was not commensurate with the relatively more pronounced hyperglycemia as compared with the control group. The question, therefore, arises whether a more appropriate insulin response in the subjects with IGT could have minimized the defect in peripheral glucose disposal and, consequently, also prevented the compensatory splanchnic response.

In both groups of subjects, arterial blood lactate increased while the splanchnic lactate balance switched to a considerable net output after glucose infusion. This finding is in accordance with previous human studies, which demonstrate that the forearm tissues have little influence on the lactate response to a glucose load, thus implying a major role of the splanchnic bed in lactate production $(21,22)$. Furthermore, the fact that splanchnic lactate balance clearly switched to a net output in the IGT group, in a sense, lends further support to the integrity of the splanchnic glucose disposal mechanisms in these subjects, specifically indicating that the glycolytic pathway is normally operative. Finally, to the extent that splanchnic lactate utilization is an index of gluconeogenesis, the current data also suggest that the antigluconeogenic effect of glucose administration is well preserved in the subjects with impaired glucose tolerance.

\section{Acknowledgments}

The authors thank Mr. Salvatore Buonerba and Mr. Alberto Frezza from the Cardiovascular Research Laboratory of the Institute of Internal Medicine I, University of Naples, for their excellent technical assistance. This work was supported by a grant from the Consiglio Nazionale delle Ricerche (Italy) (contract No. 82.02297.56 and No. 83.02811.56).

\section{References}

1. Ginsberg, H., G. Kimmerling, J. M. Olefsky, and G. M. Reaven. 1975. Demonstration of insulin resistance in maturity onset diabetic patients with fasting hyperglycemia. J. Clin. Invest. 55:454-461.

2. Reaven, G. M., R. Berstein, B. Davis, and J. M. Olefsky. 1976. Non-ketotic diabetes mellitus: insulin deficiency or insulin resistance. Am. J. Med. 60:80-88.

3. De Fronzo, R. A., D. Deibert, R. Hendler, P. Felig, and V. Soman.
1979. Insulin sensitivity and insulin binding in maturity onset diabetes. J. Clin. Invest. 63:939-946.

4. Rizza, R. A., L. J. Mandarino, and J. E. Gerich. 1981. Mechanism and significance of insulin resistance in non-insulin-dependent diabetes mellitus. Diabetes. 30:990-995.

5. Kolterman, O. G., R. S. Gray, J. Griffin, P. Burstein, J. Insel, J. A. Scarlett, and J. M. Olefsky. 1981. Receptor and postreceptor defects contribute to the insulin resistance in noninsulin-dependent diabetes mellitus. J. Clin. Invest. 68:957-969.

6. National Diabetes Data Group. 1979. Classification and diagnosis of diabetes mellitus and other categories of glucose intolerance. Diabetes. 28:1039-1057.

7. Saccà, L., M. Cicala, B. Trimarco, B. Ungaro, and C. Vigorito. Differential effects of insulin on splanchnic and peripheral glucose disposal after an intravenous glucose load in man. J. Clin. Invest. 70:117-126.

8. Saccà, L., C. Vigorito, M. Cicala, G. Corso, and R. S. Sherwin. 1983. Role of gluconeogenesis in epinephrine-stimulated hepatic glucose production in man. Am. J. Physiol. 245:E294-E302.

9. Huggett, A. S. G., and D. A. Nixon. 1957. Use of glucose oxidase, perioxidase, and $o$-dianisidine in determination of blood and urinary glucose. Lancet. II:368-370.

10. Gutmann, I., and A. W. Wahlefeld. 1974. L-(+)-Lactate determination with lactate dehydrogenase and NAD. In Methods of enzymatic analysis. H. U. Bergmeyer, editor. Second ed. Academic Press, Inc., New York. 1464-1468.

11. Leevy, C. M., C. L. Mendenhall, W. Lesko, and M. M. Howard. 1962. Estimation of hepatic blood flow with indocyanine green. J. Clin. Invest. 41:1169-1179.

12. Steele, R., H. Rostami, and N. Altszuler. 1974. A two compartment calculator for the dog glucose pool in nonsteady state. Fed. Proc. 33:1869-1876.

13. Insel, P. A., J. E. Liljenquist, J. D. Tobin, R. S. Sherwin, P. Watkins, R. Andres, and M. Berman. 1975. Insulin control of glucose metabolism in man. J. Clin. Invest. 55:1057-1066.

14. Radziuk, J., K. H. Norwich, and M. Vranic. 1974. Measurement and validation of nonsteady state turnover rates with application to the inulin and glucose system. Fed. Proc. 33:1855-1864.

15. Altszuler, N., A. Barkai, C. Bjerknes, B. Gottlieb, and R. Steele. 1975. Glucose turnover values in the dog obtained with various species of labelled glucose. Am. J. Physiol. 229:1662-1667.

16. Issekutz, B., Jr. 1977. Studies on hepatic glucose cycles in normal and methylprednisolone-treated dogs. Metab. Clin. Exp. 26:157-170.

17. De Fronzo, R. A., E. Ferrannini, R. Hendler, P. Felig, and J. Wahren. 1983. Regulation of splanchnic and peripheral glucose uptake by insulin and hyperglycemia in man. Diabetes. 32:35-45.

18. Felig, P., J. Wahren, and R. Hendler. 1978. Influence of maturityonset diabetes on splanchnic glucose balance after oral glucose ingestion. Diabetes. 27:121-126.

19. Saccà, L., R. Hendler, and R. S. Sherwin. 1978. Hyperglycemia inhibits glucose production in man independent of changes in glucoregulatory hormones. J. Clin. Endocrinol. Metab. 47:1160-1162.

20. Liljenquist, J. E., G. L. Mueller, A. D. Cherrington, J. M. Perry, and D. Rabinowitz. 1979. Hyperglycemia per se (insulin and glucagon withdrawn) can inhibit hepatic glucose production in man. J. Clin. Endocrinol. Metab. 48:171-175.

21. Jackson, R. A., N. Peters, U. Advani, G. Perry, J. Rogers, W. H. Brough, and T. R. E. Pilkington. 1973. Forearm glucose uptake during the oral glucose tolerance test in normal subjects. Diabetes. 22:442-458.

22. Radziuk, J., and R. Inculet. 1983. The effects of ingested and intravenous glucose on forearm uptake of glucose and glucogenic substrate in normal man. Diabetes. 32:977-981. 